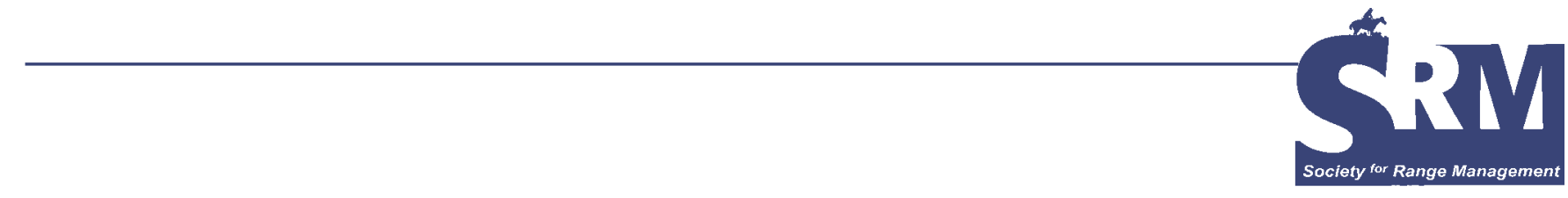

\title{
Simplifying Ecological Site Verification, Rangeland Health Assessments, and Monitoring
}

\section{By Jeffrey E. Herrick, B. T. Bestelmeyer, and Keith Crossland}

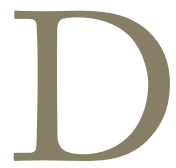

uring the past several decades, scientists and land managers in North America have increasingly recognized the importance of rangeland assessment relative to ecological potential based on soil and climate. ${ }^{1}$ The adoption of the site potentialbased "ecological site" system was recently formalized in a memorandum of understanding between the US Forest Service, the Bureau of Land Management, and the Natural Resources Conservation Service. During the same period, integration of soil and vegetation indicators ${ }^{2,3}$ has led to the development and adoption of new assessment protocols, such as "Interpreting Indicators of Rangeland Health." In addition to requiring ecological site identification based on soils (Fig. 1), this protocol includes at least two indicators that require soil excavation: "soil surface loss or degradation" and "compaction layer." The "pedestals and/or terracettes" indicator also sometimes requires excavation to determine whether erosion or deposition has resulted in the apparent elevation of plants relative to the soil surface. All three of these indicators can be difficult to assess in some ecological sites, and we have found that the best way to learn is through observation and comparison of a large number of soil profiles.

Many monitoring protocols in the United States and Canada also include soil indicators. ${ }^{5}$ Some have even argued that, "If one agrees that a variety of current and potential plant communities can occur above a conservation threshold for a particular ecological site, then monitoring vegetation has to take a backseat to monitoring soils" (p. 11). ${ }^{6}$

\section{Limitations of Existing Tools}

We have observed that one of the greatest constraints to ecological site verification and soil-based rangeland health assessment and monitoring is the inability or unwillingness of many (including, at times, ourselves) to make a suitable number of perforations of the soil surface. We have further observed that in many cases, this is due to the lack of a durable excavation instrument that is easy to carry and use. Currently available shovels are either too wide to effectively penetrate hard and stony soils, or too weak to resist the enthusiasm of rangeland scientists and managers. The "Montana Sharpshooter" is a truly formidable instrument, but suffers from both excessive mass and a blade that is too narrow to effectively clear a hole, particularly in sandy soils. This requires carrying an additional wide-bladed shovel. It is also brittle: we have managed to break tips and crack blades of Sharpshooters in extremely stony soils (admittedly while bouncing or dropping them to dislodge large stones). The objective of this paper is to describe the fabrication of a soil removal device (Fig. 2) that addresses the limitations of existing devices, simplifying both ecological site verification and rangeland assessment and monitoring.

\section{Design and Construction}

The shovel is $124 \mathrm{~cm}$ long and is constructed from a heavy gauge tile or drain spade. The thickness of the metal used to construct the blade is critical: most tile spades sold for home garden use are too thin. The blade of the model ("Razorback Solid Shank") we adapted is $14 \mathrm{~cm}$ wide at the top, $12.5 \mathrm{~cm}$ at the base of the curved tip, and $40 \mathrm{~cm}$ long. The blade is $2.4 \mathrm{~mm}$ (0.093 inches, 13 gauge) thick.

Most of these shovels have a wood shank that connects the handle with the blade stem. The following describes how to replace this with a steel shank that increases mass and durability, and improves the balance of the shovel. Appropriate safety equipment should be used during all of the steps described here: 


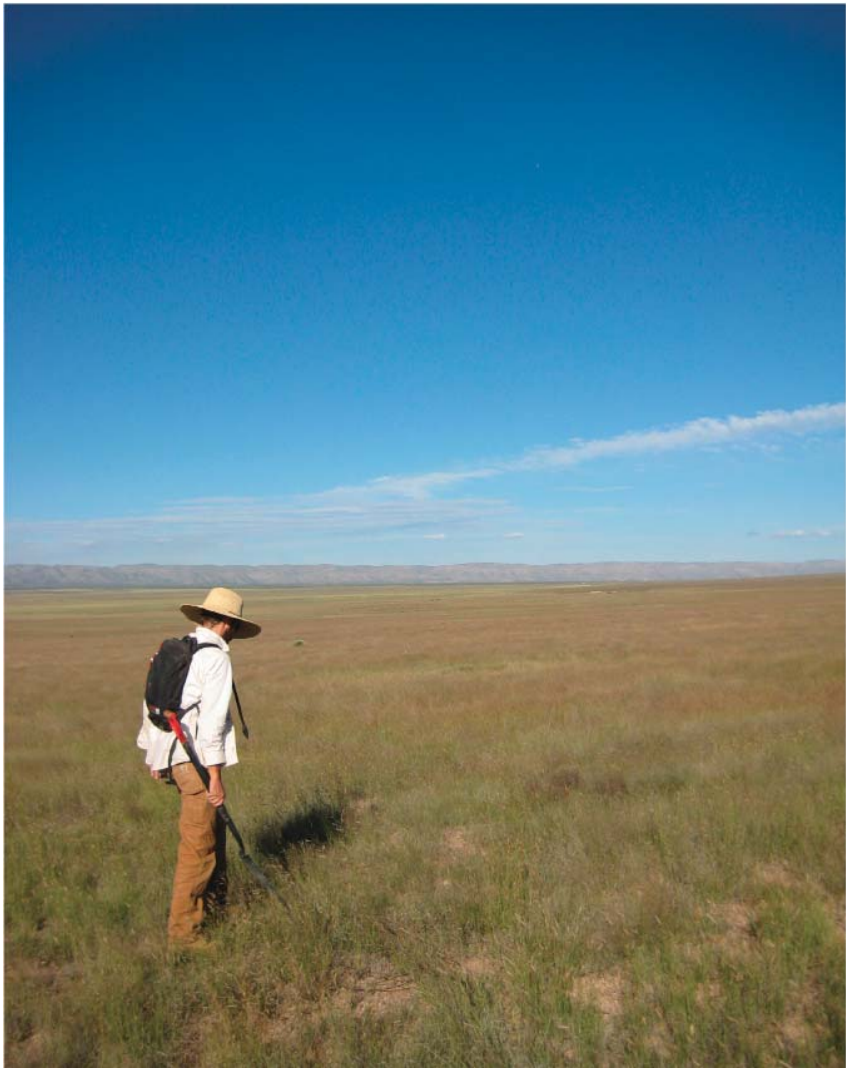

Figure 1. Ecological site identification in southern New Mexico.

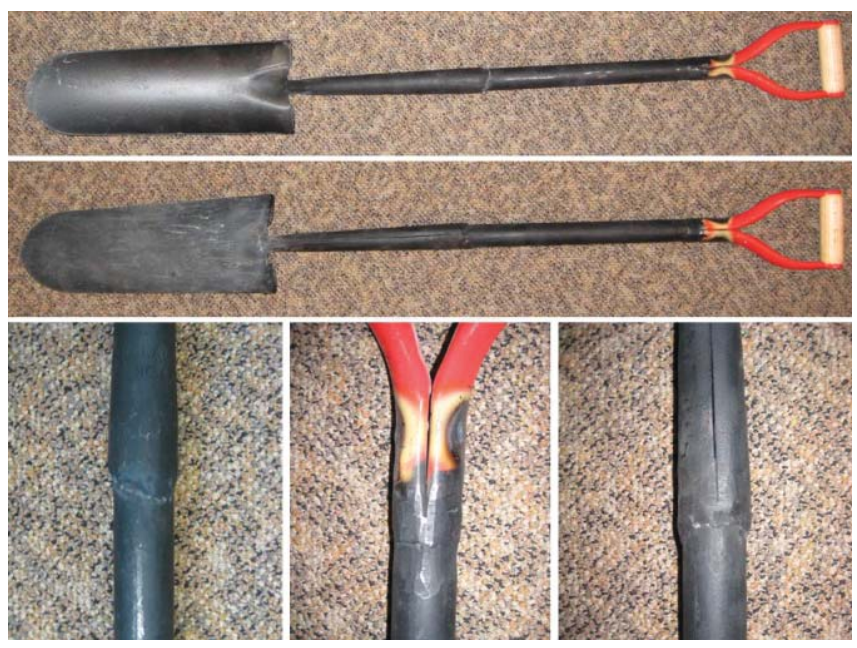

Figure 2. Modified shovel emphasizing new welds.

1) Remove the shank.

2) Use a grinder or wire brush to clean any edges or burrs.

3) Cut a piece of schedule 40 steel pipe to the appropriate length. The diameter of the pipe should be similar to the diameter of the original shank. When inserted into the blade stem and handle, the distance from the top of the handle to the top of the blade should be about $84 \mathrm{~cm}$.
4) Insert the shank into the blade stem and weld.

5) Weld the product of step \#4 to the handle.

6) Weld shut the blade shank and any open rivet holes.

7) Smooth welds with a metal file or grinder.

8) If desired, paint the shank and welds to minimize rusting.

\section{Summary and Conclusions}

If properly assembled, the shovel should have a center of balance at its approximate geometric center $(\sim 60 \mathrm{~cm})$ and be virtually unbreakable. At $2.8 \mathrm{~kg}$, it is heavy enough to drive into hard soils, but significantly lighter than the Montana Sharpshooter (over $4.2 \mathrm{~kg}$ ). In conclusion, we hope that this shovel, if not our own enthusiasm for excavation, will make it easier for others to dig not just one, but several holes when verifying ecological sites and evaluating soil indicators.

\section{Acknowledgments}

We thank Jose Ramirez and Nick Padilla for fabricating the prototypes described here. We also acknowledge the anonymous burrowers who shared several similar designs with us, and the innumerable individuals who have proposed and published soil and ecological frameworks that require a good shovel.

\section{References}

1. Briske, D. D., S. D. Fuhlendorf, and F. E. Smeins. 2005. State-and-transition models, thresholds, and rangeland health: a synthesis of ecological concepts and perspectives. Rangeland Ecology and Management 58:1-10.

2. National Research Council. 1994. Rangeland health: new methods to classify, inventory, and monitor rangelands. Washington, DC, USA: National Academy Press. 200 p.

3. Society for Range Management Task Group on Unity in Concepts and Terminology. 1995. New concepts for assessment of rangeland condition. Journal of Range Management 48: 271-282.

4. Pellant, M., P. Shaver, D. Pyke, and J. E. Herrick. 2005. Interpreting indicators of rangeland health. Version 4. Denver, CO, USA: Bureau of Land Management. Interagency Technical Reference 1734-6. Available at: http://usda-ars.nmsu.edu/JER/ Monit_Assess/monitoring.htm.

5. Herrick, J. E., E. Garcia-Moya, W. Willms, B. Bestelmeyer, P. Sundt, and W. Barnes. 2006. Arid and semi arid rangeland monitoring in North America. Secherresse 17: 235-241.

6. West, N., K. McDaniel, E. L. Smith, P. Tueller, and S. Leonard. 1994. Monitoring and interpreting ecological integrity of arid and semi-arid lands of the western United States. Las Cruces, NM, USA: New Mexico Range Improvement Task Force. 15 p.

Authors are Research Soil Scientist, jherrick@nmsu.edu (Herrick), and Research Ecologist (Bestelmeyer), USDA-ARS Jornada Experimental Range, MSC 3JER, Nerw Mexico State 
University, Box 30003, Las Cruces, NM 88003, USA; and Graduate Student, Dept of Plant and Environmental Science, MSC 3Q, Box 30003, New Mexico State University, Las Cruces, NM 88003, USA (Crossland). This work was supported by the NSF Jornada LTER (DEB 0080412) and the
USDA-ARS Jornada Experimental Range. Mention of trade names or commercial products in this article is solely for the purpose of providing specific information and does not imply recommendation or endorsement by the US Department of Agriculture. 